\title{
Dermoscopy of Tick Bite
}

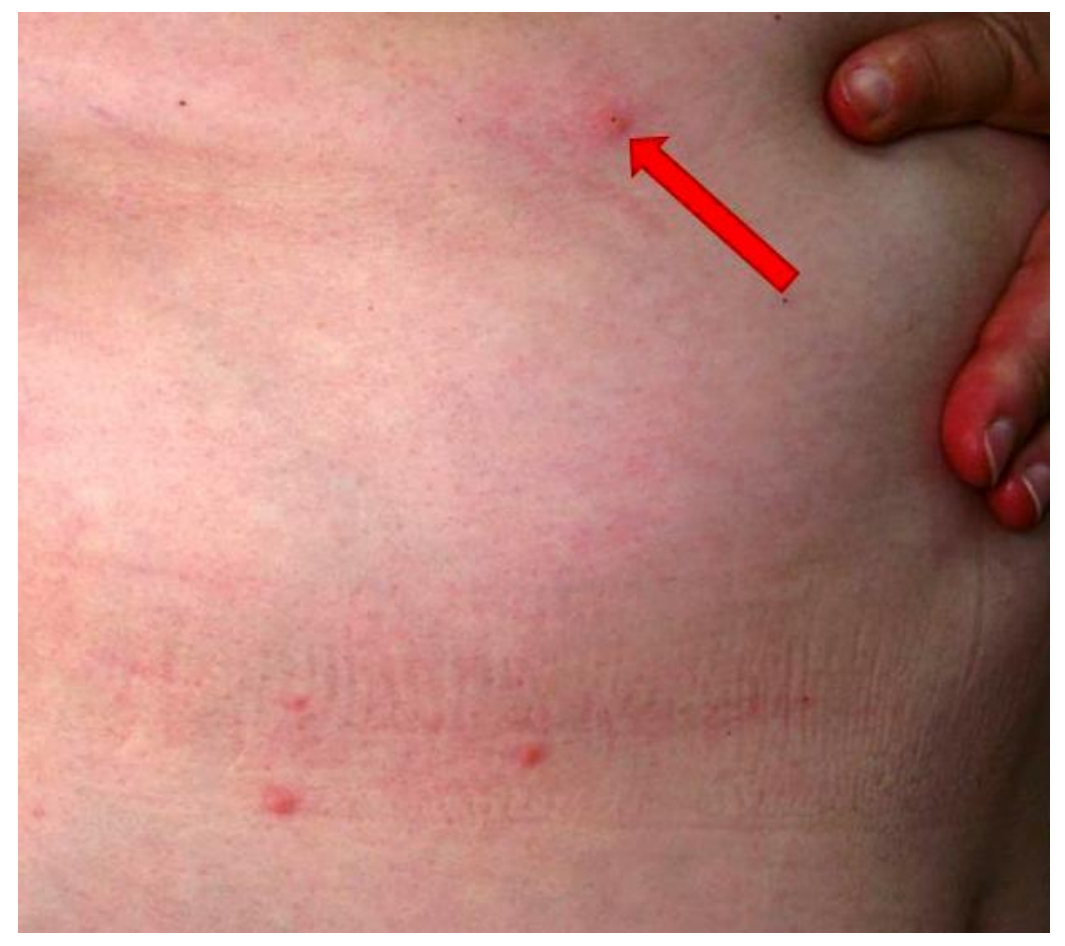

FIGURE 1. Numerous, intensively pruritic, erythematous papules on the patients' trunk. The arrow shows the site of the dermoscopic picture.

\section{Efstathios Rallis \\ Department of Dermatology, Veterans Administration Hospital (NIMTS), Athens, Greece}

E-mail: efrall@otenet.gr

Received July 29, 2010; Revised August 12, 2010; Accepted August 16, 2010; Published September 1, 2010

KEYWORDS: dermoscopy, tick

A 54-year-old woman presented with a 12-h history of the appearance of numerous, intensively pruritic, erythematous papules on her trunk (Fig. 1). Dermoscopy showed the presence of small-sized ticks in the majority of lesions (Fig. 2). By using medium-tipped, angled forceps, every tick was grasped as close to the skin as possible and tracked out vertically. A total of 28 ticks were finally removed. 


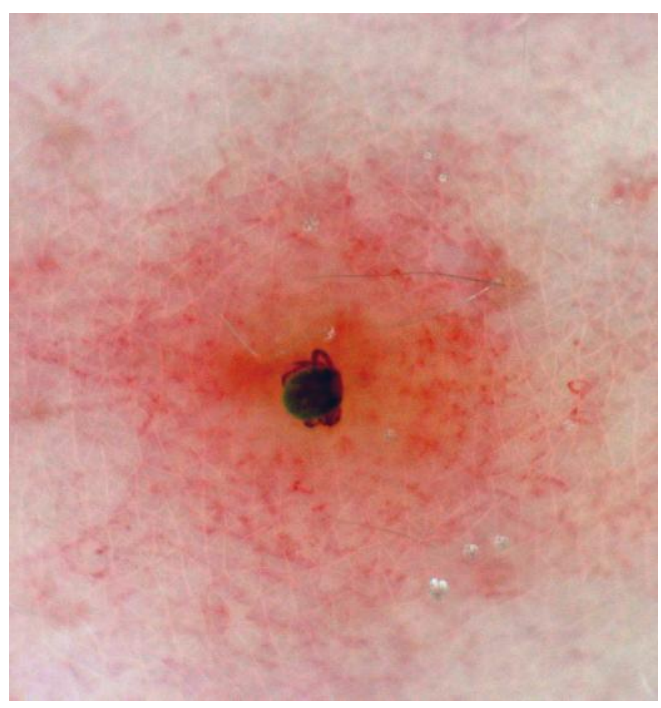

FIGURE 2. Dermoscopic findings of tick bite.

Ticks are blood-feeding ectoparasites usually found in grass and woods, and on pets. They harbor and spread a variety of pathogens to their hosts, and can cause Lyme disease, Rocky-Mountain spotted fever, Colorado tick fever, babesiosis, ehrlichiosis, tularemia, and relapsing fever[1]. Twenty-four to $48 \mathrm{~h}$ of the ticks' attachment to the host are required before infection occurs, thus their early removal is useful in order to prevent diseases.

The application of dermoscopy to detect the tick in the lesion is easy, inexpensive, and effective for confirming the diagnosis[2,3].

\section{REFERENCES}

1. $\quad$ Bratton, R.L. and Corey, G.R. (2005) Tick-borne disease. Am. Fam. Physician 71, 2323-2332.

2. Oiso, N., Kawara, S., Yano, Y., and Kawada, A. (2010) Diagnostic effectiveness of dermoscopy for tick bite. J. Eur. Acad. Dermatol. Venereol. 24, 231-232.

3. Zalaudek, I., Giacomel, J., Cabo, H., et al. (2008) Entodermoscopy: a new tool for diagnosing skin infections and infestations. Dermatology 216, 14-23.

This article should be cited as follows:

Rallis, E. (2010) Dermoscopy of tick bite. TheScientificWorldJOURNAL 10, 1705-1706. DOI 10.1100/tsw.2010.175. 


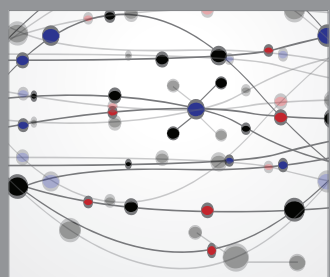

The Scientific World Journal
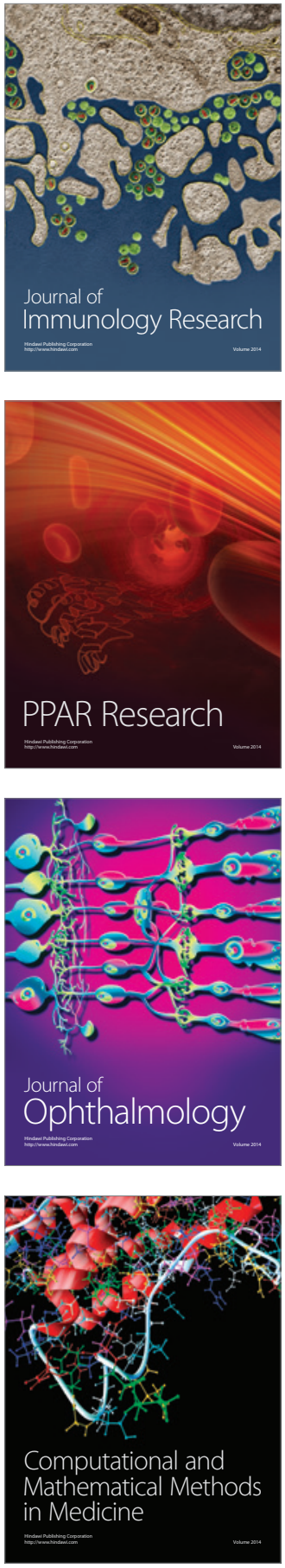

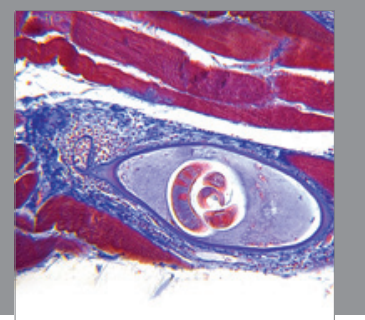

Gastroenterology

Research and Practice
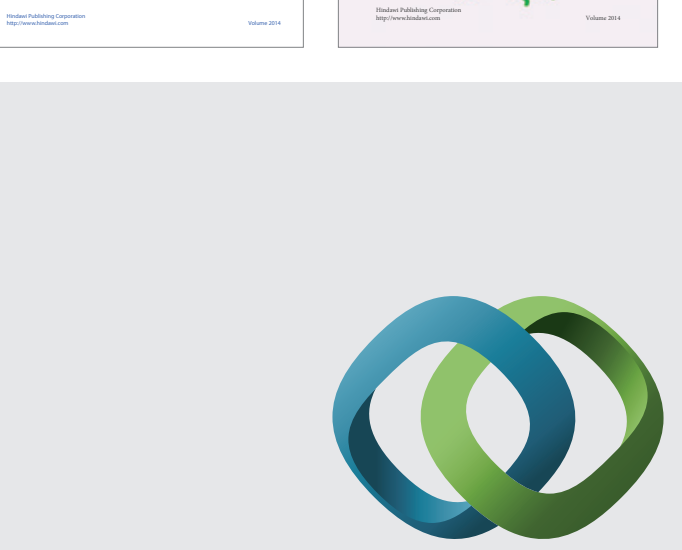

\section{Hindawi}

Submit your manuscripts at

http://www.hindawi.com
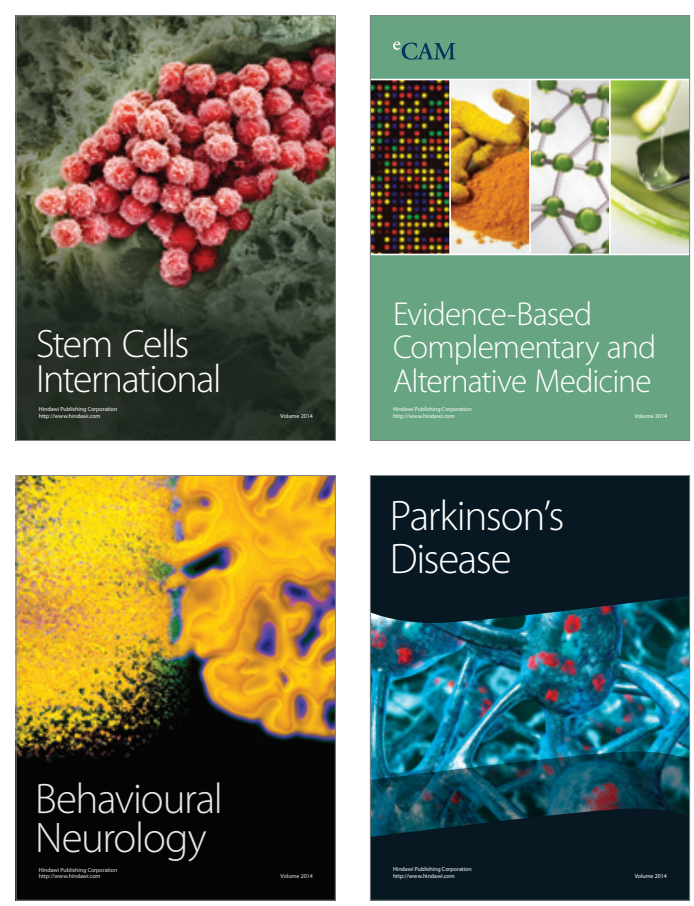

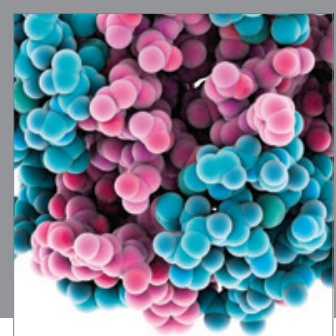

Journal of
Diabetes Research

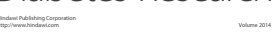

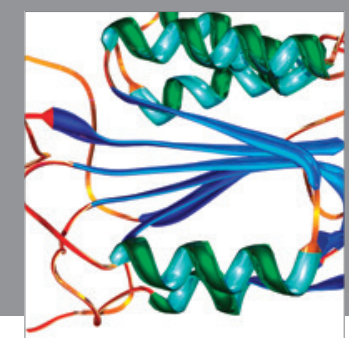

Disease Markers
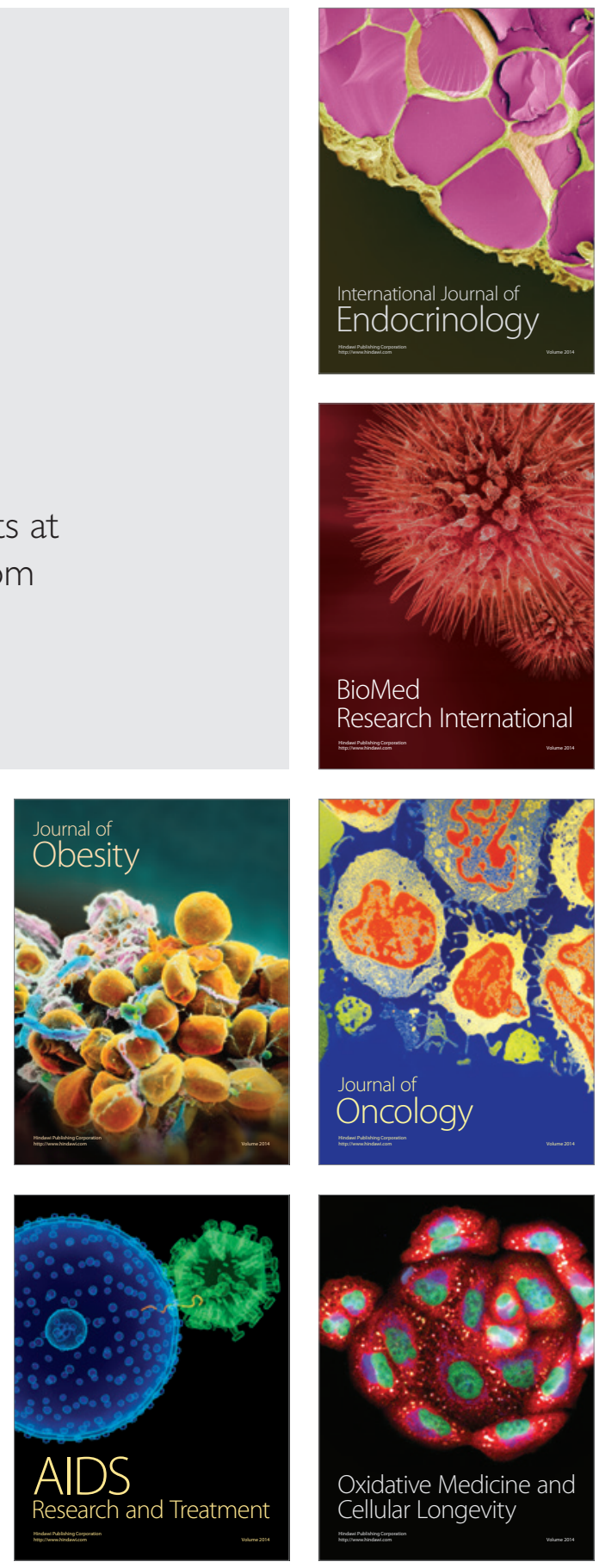